\title{
Inventário de Percepção de Suporte Familiar (IPSF): Estudo Componencial em duas Configurações
}

Perception of family support inventory:

Study of components in two sets

Makilim

Nunes Baptista

Universidade

São Francisco 


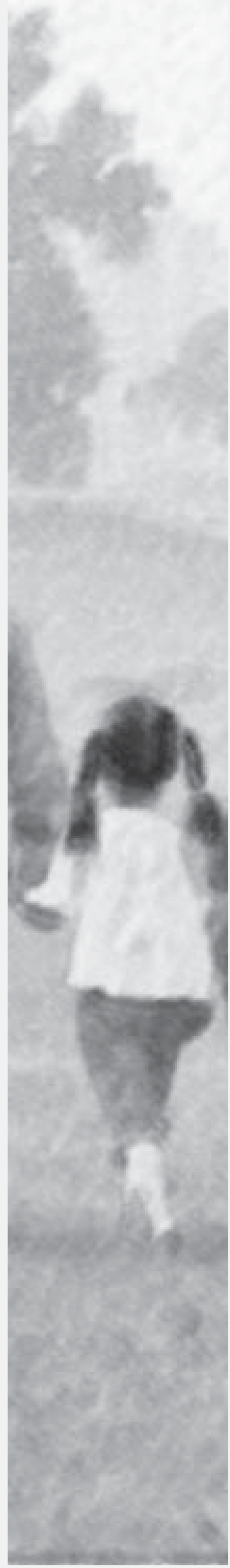

Resumo: O objetivo deste estudo foi o de comparar os componentes do inventário de percepção de suporte familiar (IPSF) em duas configurações de participantes, por intermédio de análise fatorial. A amostragem da segunda configuração foi constituída por mil e sessenta e quatro estudantes do ensino médio e universitário, com idades que variavam entre dezessete e sessenta e quatro anos, de ambos os sexos, de instituições particulares e públicas do Estado de São Paulo. Foi utilizada a análise de componentes principais, com rotação oblimim nessa configuração. A análise fatorial extraiu a presença de três fatores, intitulados afetivoconsistente, adaptação e autonomia, o que expressou uma variância total de $41,433 \%$ do construto. O IPSF demonstrou ser um inventário com dimensões bem definidas, sendo que todos os itens possuíram cargas fatoriais acima de 0,30 . O fator afetivo-consistente demonstrou precisão de 0,91, expresso pelo alfa de Cronbach, seguido pelo fator inadaptação, com alfa de 0,90, e, por último, o fator autonomia expressou um alfa de 0,78 , além do alfa da escala total ser de 0,93 . As cargas fatoriais dos itens foram sempre superiores a 0,30.O IPSF também expressa as dimensões encontradas em diversos instrumentos e teorias internacionais sobre $\mathrm{o}$ construto suporte familiar. As comparações das configurações são discutidas. Outras evidências de validade, bem como a padronização do IPSF, se fazem necessárias, a fim de se obter outros dados psicométricos do inventário, já que o processo de validação de qualquer instrumento se comprova de forma dinâmica e constante.

Palavras-chave: validade, precisão, suporte familiar, IPSF.

Abstract: The goal of this study was to compare the components of the perception of family support inventory (IPSF) in two sets of participants, through factorial analysis. The sample from the second set was formed by 1064 high school and college students, who were from 17 to 64 years old, both genders, from private and public institutions of the São Paulo State. The main components' analysis was used with oblimim rotation in this set. Factor analysis extracted the presence of three factors, entitled affective-consistent, adaptation and autonomy, what expressed $41,433 \%$ of the total variance of the construct. The IPSF appears to be an inventory with well defined dimensions, so that all items had factor loadings higher than 0,30 . The factor affective-consistent demonstrated reliability of 0,91 , demonstrated by Cronbach's a, followed by the factor called inadaptation, with a 0,90 and, finally, the factor autonomy, expressed by a 0,78 , besides total scale's a 0,93. The factor loading from the items were always higher than 0,30. The IPSF also expresses the dimensions found in other instruments and international theories about family support. The configurations comparisons are discussed. Other validity evidences, as standardization of IPSF, are necessary to obtain other psychometric data from the inventory, considering that the process of validation from any instrument finds its reliability in a dynamic and constant way.

Key words: validity, reliability, family support, IPSF. 


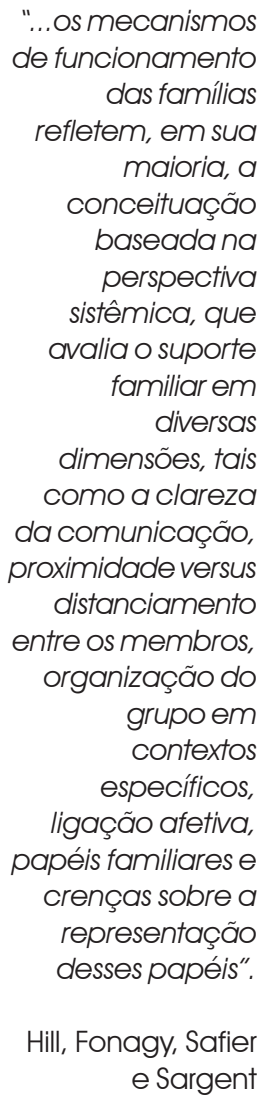

Hill, Fonagy, Safier e Sargent

A família desempenha um importante papel socializador em grande parte das sociedades modernas, apesar das modificações que esse grupo social vem sofrendo nas últimas décadas, relacionados com a pósmodernidade, tais como a inserção da mulher no mercado de trabalho, o número crescente de separações e divórcios, o aumento de famílias monoparentais e coabitações, dentre outros (Allen; Blieszner e Roberto, 2000). A qualidade das relações familiares está associada ao ajustamento emocional e comportamental entre crianças e adultos, ou mesmo entre adultos. Segundo Hill, Fonagy, Safier e Sargent (2003), os mecanismos de funcionamento das famílias refletem, em sua maioria, a conceituação baseada na perspectiva sistêmica, que avalia o suporte familiar em diversas dimensões, tais como a clareza da comunicação, proximidade versus distanciamento entre os membros, organização do grupo em contextos específicos, ligação afetiva, papéis familiares e crenças sobre a representação desses papéis.

Atualmente, muitos artigos abordam, mais especificamente, os serviços de acompanhamento de famílias bem como a importância do suporte familiar e social para amostras específicas e sua relação com aspectos psicológicos e sociais. O suporte familiar, por exemplo, está associado a traços de personalidade, como apontam Reti et al. (2002), por intermédio de uma pesquisa de acompanhamento com setecentos e quarenta e dois pacientes, acompanhados por psiquiatras, e que possuíam transtornos do eixo I do DSM-IV, que reportaram baixo carinho parental e intromissão da família e possuíam mais traços de neuroticismo, baixa responsabilidade, menos direcionamento de vida e aumento de esquiva de situações de vida. No mesmo sentido, Santos (2006) encontrou, em uma amostra de trezentos e quarenta e seis universitários, correlação positiva entre afetividade familiar do IPSF, socialização e extroversão no Big Five, correlação positiva entre consistência familiar e autonomia, com o fator realização, autonomia com abertura, inadaptação familiar e neuroticismo, e, por último, correlação negativa entre afetividade e consistência familiares, com o fator neuroticismo, indicando tais associações entre fatores de personalidade com dimensões de percepção de suporte familiar.

Johnson et al. (2002) relataram, em um estudo epidemiológico prospectivo com seiscentas e cinqüenta e nove famílias, que crianças maltratadas possuíam maiores dificuldades interpessoais durante a adolescência e mais tentativas de suicídio quando comparadas a crianças não maltratadas. Harris \& Molock (2000) associaram o suporte familiar inadequado com ideação suicida e sintomatologia de depressão em cento e oitenta e sete estudantes africanos selecionados por conveniência, já que altos níveis de coesão e suporte familiar estavam correlacionados com baixos níveis de depressão e ideação suicida.

O suporte familiar também está relacionado com algumas características comportamentais de crianças. Kashani et al. (1994), ao estudarem cem crianças que realizavam tratamento psiquiátrico ambulatorial, concluíram que aquelas que possuíam baixa percepção de suporte familiar e social tinham maiores dificuldades de fixar a atenção, eram mais violentas com os pares e destruíam mais os bens materiais, além de serem menos cooperativas em diversas atividades e de 
possuírem maiores pontuações em desesperança. A adequada percepção de suporte familiar, bem como a qualidade das relações com os pares, também influenciam a auto-estima de adolescentes, sendo que o suporte familiar também foi preditivo na qualidade das relações sociais (Franco e Levitt, 1998).

Xiaolian et al. (2002) relataram a importância do suporte familiar nos comportamentos de autocuidados em doentes crônicos, já que foi observada correlação entre percepção de suporte familiar e aumento de motivação para autocuidados com o estado de saúde. Os programas que incentivam a família, como o suporte em diversas situações, também vêm sendo bastante abordados nas literaturas atuais. Clark (2001), por exemplo, relata a importância do suporte familiar para adolescentes que engravidam, já que as mesmas passam por situações difíceis nesse período. Já para Kirk (2003), os centros de atenção à criança devem se preocupar com o desenvolvimento de uma abordagem mais abrangente sobre os processos de desenvolvimento infantil, já que, motivando a participação dos pais no desenvolvimento infantil, podem promover a resiliência familiar e facilitar a inclusão dessas famílias no meio social.

Sendo assim, parece fundamental o desenvolvimento de instrumentos que avaliem a percepção de suporte familiar, pois, no Brasil, pouco se conhece ou se pesquisa sobre o tema em questão, principalmente o que se encontra relacionado ao desenvolvimento e utilização desses inventários (Baptista, 2005). Segundo Bray (1995), vêm-se notando, nos Estados Unidos, que a proliferação de medidas válidas e fidedignas na área familiar é um reflexo da prática clínica naquele país; no entanto, alguns problemas ainda se verificam na área de pesquisa, o que dificulta maiores conquistas científicas. Dentre as dificuldades, os maiores problemas na área de avaliação familiar se justificam pela falta de uma teoria unificada sobre o funcionamento familiar e o não consenso a respeito do que seria uma família saudável e uma família disfuncional, provavelmente por esses aspectos não contarem com medidas-padrão, também chamadas de gold standards. O próprio autor comenta, ainda, que os psicólogos familiares possuem diversos tipos de preconceitos a respeito de medidas estandardizadas, além da falta de hábito em se trabalhar com tais medidas nos protocolos de avaliação.

Algumas características do suporte familiar são bastante investigadas por teóricos e autores que desenvolveram instrumentos de medida de suporte familiar. Olson, Russell e Sprenkle (1983) desenvolveram um modelo teórico circumplexo dos sistemas familiares e discorrem sobre vários aspectos importantes das relações familiares, tais como a coesão, a adaptabilidade e a comunicação familiar. A coesão estaria relacionada aos tipos de vínculos que os membros familiares estabelecem, que incluem a forma de realização dos processos de decisão, o tempo que as pessoas passam juntas, os interesses familiares comuns, os limites, as ligações entre as pessoas e os interesses nas atividades recreativas. A adaptabilidade seria a habilidade de o sistema familiar transformar a estrutura de poder e as regras nos relacionamentos, em resposta a situações geradoras de estresse. Por conseguinte, a comunicação seria uma dimensão crítica nas famílias, o que proporcionaria, inclusive, a 
facilitação das características da coesão e adaptabilidade. Ela seria composta pela empatia entre os membros, o ouvir reflexivo e suportivo, além da expressão e compartilhamento afetivo entre os membros familiares.

Bray (1995) relata pelo menos quatro fatores que vêm sendo observados nas teorias sobre o funcionamento familiar, a saber, a composição da família, os processos familiares, a afetividade e a organização familiar. A composição familiar está diretamente relacionada com o tipo de estrutura observada, tal como famílias nucleares, pais divorciados, presença e ausência de filhos, etc. Já os processos familiares dizem respeito aos fatores comportamentais e interacionais da família, tais como os conflitos, as diferenças entre os membros da família, comunicação, resolução de problemas, controle e autonomia. A afetividade seria avaliada pelas expressões de afeto entre os membros familiares que contextualizam os processos familiares. Por último, a organização familiar se refere às regras de funcionamento da família.

Os instrumentos utilizados no Brasil, que avaliam construtos associados com a percepção de suporte familiar, tais como estilo parental, percepção dos pais, entrevista familiar estruturada e satisfação com a família, foram descritos em Baptista (2005). Já alguns instrumentos relacionados são mais citados na literatura internacional e parecem ser parâmetros para o desenvolvimento e validação de instrumentos de percepção de suporte familiar; dentre eles, pode-se apontar o family assessment device - FAD (Epstein, Baldwin e Bishop, 1983), o parental bonding instrument (Parker, Tupling e Brown, 1979), o family satisfaction scale (Carver e Jones, 1992) e o perceived social support from family - PSS-Fa (Procidano e Heller, 1983).

Em outro estudo da satisfação do grupo familiar sobre sentimentos e atitudes de interesses e habilidades entre os seus componentes, foi utilizada a escala family satisfaction scale. Trata-se de um instrumento de vinte itens que avalia a satisfação familiar de acordo com quatro domínios: satisfação geral com a vida familiar e membros familiares, aceitação e afeto entre os componentes do grupo familiar, consistência e previsão de condutas entre os componentes e compromisso e confiança em relação à família. Após a validação do instrumento, concluiu-se que essas dimensões se relacionam com os mecanismos de como os membros interagem e funcionam entre si; no entanto, essa escala não é capaz de avaliar comportamentos específicos que estejam associados a problemas ou a disfunções familiares (Carver e Jones, 1992).

O FAD é um inventário constituído por sessenta itens, em escala tipo likert de quatro pontos (1-concorda totalmente, 2-concorda, 3-discorda e 4-discorda totalmente), que avalia o funcionamento familiar em sete dimensões distintas, dentre as quais solução de problemas, comunicação, funções/papéis, receptividade afetiva, envolvimento afetivo, controle comportamental e funcionamento geral da família. É utilizado em famílias que possuem membros com doenças crônicas e psiquiátricas, e os resultados por item estabelecem o parâmetro com variação de 1 (funcionamento familiar saudável) a 4 (funcionamento familiar não saudável). Na dimensão solução de problemas, avalia-se a 
habilidade familiar de resolver problemas e a capacidade funcional da família em manter um nível de funcionamento familiar efetivo. $\mathrm{Na}$ comunicação, avalia-se a habilidade definida como a troca de informação entre os membros familiares, na qual o foco é se as mensagens verbais são claras com respeito ao conteúdo e diretas no sentido de que a pessoa com quem se fala é a pessoa para quem se destina a mensagem. Em papéis/ funções, focaliza-se o fato de a família ter estabelecido modelos de comportamento para lidar com um conjunto de funções familiares que incluem provisão de recursos de alimentação, apoio, suporte para o desenvolvimento pessoal, manutenção e gerenciamento dos sistemas familiares, bem como de gratificação sexual adulta. Inclui considerar se as tarefas são designadas de forma clara e equilibradas entre os membros e se as tarefas são desempenhadas de maneira responsável por seus membros. $\mathrm{Na}$ receptividade afetiva, avalia-se habilidade pela qual os membros da família são capazes de vivenciar emoções apropriadas frente a uma variedade de estímulos, tanto de bem-estar quanto de emoção de emergência. No envolvimento afetivo, estima-se a extensão com que os membros da família estão interessados e valorizam as atividades e as preocupações dos outros membros. No controle comportamental, avalia-se a maneira pela qual a família expressa e mantém padrões de comportamento de seus membros, o comportamento em situação de perigo, social e emocional, e o tipo de controle considerado flexível, rígido, indiferente ou caótico. Por último, no funcionamento familiar geral, obtém-se uma estimativa total de saúde da família.

O perceived social support from family - PSSFa (Procidiano e Heller, 1983) é um inventário com vinte itens, com resposta dicotômica (sim ou não), composto por apenas um fator, derivado de fatoração ortogonal, que aborda um conteúdo misto de necessidade de suporte, informação e realimentação, provindos da família. Esse inventário contraria os demais de sua área por se apresentar em apenas uma dimensão e ser dicotômico.

O parental bonding instrument (Parker, Tupling e Brown, 1979) foi desenvolvido para medir especificamente duas dimensões antagônicas no suporte familiar, dentre elas, superproteção versus permissão de autonomia e independência, e rejeição e indiferença versus carinho. $\mathrm{O}$ instrumento é provido de vinte e cinco afirmações, divididas em sete itens sobre superproteção, seis sobre permissão de autonomia e independência, seis itens sobre rejeição e indiferença, e seis itens sobre carinho, que lista várias atitudes e comportamentos dos familiares em relação ao adolescente.

O inventário de percepção de suporte familiar (IPSF) foi avaliado inicialmente por intermédio de análise fatorial. O KMO inicial foi de 0,92, e o teste de esferidade de Barlett foi significativo ao nível de 0,0001, em que foi explicado $42,80 \%$ da variância total. O IPSF foi composto, inicialmente, de quatro fatores, com quarenta e seis itens, a saber, inadaptação, contendo catorze itens, que mensura a percepção de baixo ou inadequado suporte familiar; afetividade, com dez itens, que representa as relações afetivas intrafamiliares, inclusive os interesses dos membros e expressões afetivas verbais e nãoverbais; consistência, com onze itens, que representa os papéis e regras intra-familiares bem como as estratégias de enfrentamento familiares para problemas, e, por último, a 
autonomia, com oito itens, que representou o quanto o indivíduo sente que possui incentivo e liberdade para se expressar e ter autonomia. Os índices de confiabilidade, representados pelo alfa de Crombach, foram de 0,88 para inadaptação, 0,86 para afetividade, 0,83 para consistência, 0,81 para autonomia, e, por fim, 0,93 para todo o inventário (Baptista, 2005).

Inicialmente, a pesquisa de Baptista (2005) utilizou trezentos e quarenta e seis estudantes universitários de uma universidade particular do interior de São Paulo, com média de idade de 24,67 (DP=6,36), sendo 76,6\% do sexo feminino; o método utilizado no estudo foi a análise dos componentes principais, com rotação Varimax. Os resultados encontrados pela análise fatorial foram condizentes com a literatura sobre suporte familiar, especificamente com os instrumentos que avaliam tal construto (Baptista, 2005). Sendo assim, o objetivo desta pesquisa foi o de comparar os resultados da análise fatorial na configuração amostral citada anteriormente com a configuração descrita na metodologia atual, com um número de participantes maior (descrita a seguir).

\section{Participantes}

Foram participantes um total de mil e sessenta e quatro estudantes do ensino médio e universitário, com idades que variavam de dezessete a sessenta e quatro anos $(M=23,35 ; D P=6,05$ anos), de instituições particulares e públicas do Estado de São Paulo. A maior parte dos participantes foi do sexo feminino, que constituiu $73,7 \%$ do total, e o estado civil foi dividido da seguinte maneira: $82,2 \%$ dos participantes solteiros, 9,9\% casados, 2,1\% viúvos, divorciados e recasados, e 5,8\% não responderam tal questão.

\section{Procedimento e análise}

Todos os participantes concordaram com a testagem por intermédio da assinatura do termo de consentimento livre e esclarecido, tendo o projeto sido aprovado por Comitê de Ética. As aplicações ocorreram de forma coletiva, nas salas de aula, utilizando-se aproximadamente vinte minutos para o preenchimento do mesmo. Foram tomados cuidados, como a explicação do objetivo do estudo, da não existência de resposta correta e do cuidado em responder o que mais se aproximava da percepção do indivíduo. Para a análise das dimensões, utilizaram-se, inicialmente, as rotações equamax, quartimax e oblimin para avaliar qual dessas respondia melhor ao construto. Também foi calculada a precisão do instrumento, utilizando-se o alfa de Cronbach também por intermédio do statistical package for social sciences, versão 10.0 .

\section{Resultados}

A análise dos componentes principais, com rotação oblimin, mostrou-se mais adequada na análise da segunda configuração, principalmente levando-se em conta o número de itens que não atingiam a carga fatorial mínima convencionada pelo pesquisador, ou seja, 0,30, e o tipo de agrupamento, de acordo com os princípios teóricos adotados na construção do instrumento (Baptista, 2005). Inicialmente, a solução baseada em quatro fatores não se mostrou satisfatória, já que dez itens da dimensão inicialmente denominada afetividade se agruparam com seis itens da dimensão denominada consistência, indicando que essas duas dimensões possuíam uma tendência de estarem agrupadas e 
mensurarem questões de uma mesma dimensão. Procedeu-se então à solicitação de uma mesma análise com componentes principais, mas agora com o limite de três dimensões, com cargas fatoriais acima de 0,30 e eingenvalues acima de 1,0, a fim de se verificar se outros itens dessas duas dimensões iriam se agrupar novamente em uma mesma dimensão.

Sendo assim, observou-se a junção de itens das dimensões anteriores, denominadas afetividade e consistência, e foram mantidos os itens das dimensões adaptação e autonomia; portanto, o instrumento final consta de três grandes dimensões. É interessante notar que um item, inicialmente denominado item 18 ("Eu sinto que deveria ter nascido em outra família") foi retirado, em função de apresentar carga fatorial discrepante da exigida inicialmente no modelo (acima de 0,30), e dois itens foram alocados em duas dimensões (itens 12 e 19 - "Minha família me faz sentir que posso cuidar de mim, mesmo quando estou sozinho (a)", "Em minha família, há privacidade"). A decisão de mantê-los na dimensão denominada autonomia se deu por duas justificativas: em primeiro lugar, as maiores cargas fatoriais eram na dimensão autonomia, e, em segundo lugar, semanticamente, o conteúdo estava também mais relacionado a essa dimensão.

Analisadas as diferentes soluções fatoriais, optou-se por aquela produzida pelo método dos componentes principais, com rotação oblimim, normalizado por Kaiser. O KMO definitivo foi de 0,95, e o teste de esfericidade de Bartlett foi significativo ao nível de 0,0001 ( $\ddot{e}^{2}=17041,35$; $\mathrm{gl}=861$ ), sendo os eingenvalues sempre superiores a 2,5. A variância total explicada pelas três dimensões foi de 41,43 (Tabela 1).

O scree plot é apresentado na Figura 1, e indicou a preleção por três grandes fatores bem diferenciados, conforme a figura.

\section{Scree Plot}

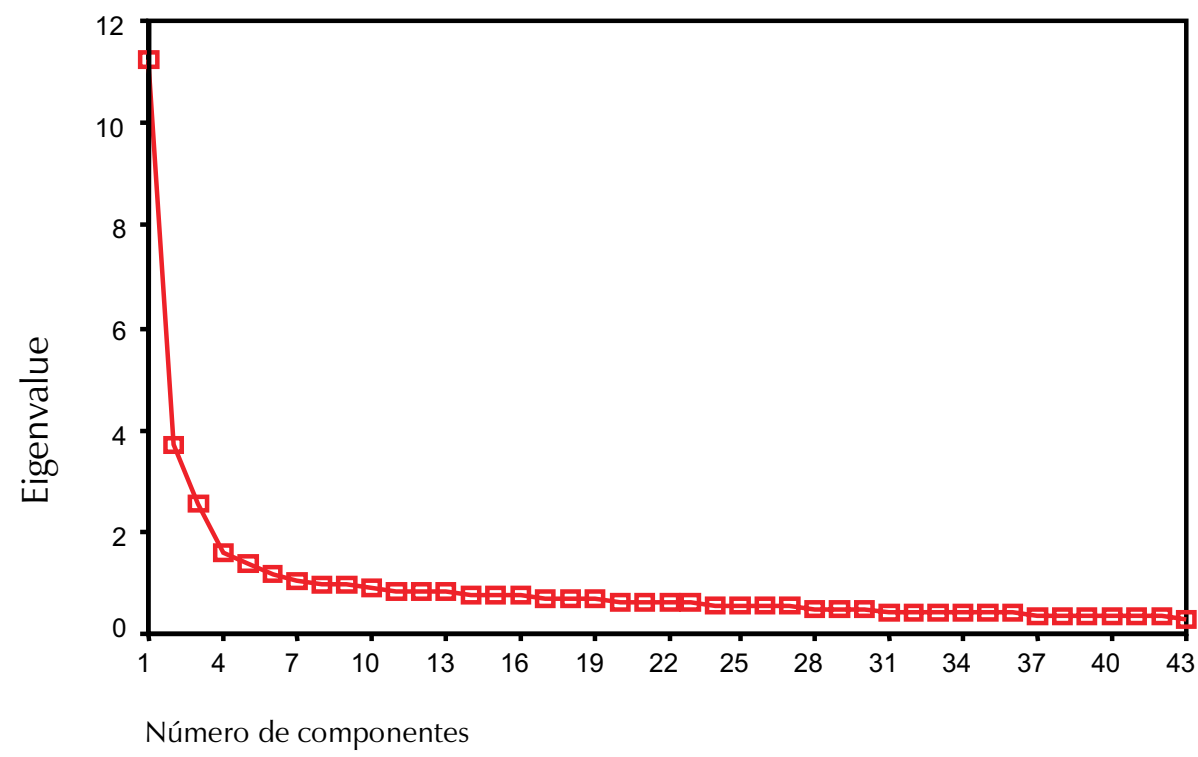

Figura 1 - Gráfico de sedimentação dos Eingenvalues. 
Na tabela 1, são apresentadas as cargas fatoriais dos itens do inventário de percepção de suporte familiar, convertido em cinco interações do modelo, no qual constam os itens finais, ou seja, o total de quarenta e dois itens, sempre com cargas fatoriais acima de 0,30, além das variâncias, comunalidades e eingenvalues.

Tabela 1 - Cargas fatoriais dos componentes principais com rotação Obllimin, eigenvalues, variância explicada e comunalidades do IPSF

\section{Componentes}

Os membros da minha família expressam interesse

e carinho uns com os outros.

Os membros de minha família se tocam e se abraçam.

Minha família me proporciona muito conforto emocional.

Em minha família, opinamos o que é certo/errado buscando

o bem-estar de cada um.

As pessoas da minha família se sentem próximas umas das outras.

Em minha família, demonstramos carinho através das palavras.

Na solução de problemas, a opinião de todos na família é levada em consideração.

Minha família discute seus medos e preocupações.

Minha família me faz sentir melhor quando estou aborrecido(a).

Os membros da minha família expressam claramente pensamentos e emoções uns com os outros.

As pessoas da minha família gostam de passar o tempo juntas.

Minha família discute junto antes de tomar uma decisão importante.

As pessoas da minha família sabem quando alguma coisa ruim aconteceu comigo, mesmo eu não falando. Meus familiares me elogiam.

Em minha família, há uma coerência entre as palavras e os comportamentos.

Meus familiares servem como bons modelos em minha vida.

Em minha família, as tarefas são distribuídas adequadamente.

As pessoas, na minha família, seguem as regras estabelecidas entre eles.

Minha família sabe o que fazer quando surge uma emergência.

Cada um, em minha família, tem deveres e responsabilidades específicas.

\section{1}

23 Comunalidade

0,70

0,11

0,69

0,20

0,69

0,15

0,67

0,35

0,67

0,11

0,67

0,48

\begin{tabular}{|l|l|}
\hline 0,63 & 0,63 \\
\hline 0,63 & 0,36 \\
\hline
\end{tabular}

0,61

0,36

0,61

0,31

0,60

0,39

0,57

0,30

0,57

0,60

0,55

0,49

0,55

0,44

\begin{tabular}{l|l}
0,53 & 0,40
\end{tabular}

0,50

0,35

0,47

0,30

0,40

0,46

0,36

0,57 


\begin{tabular}{|c|c|c|c|c|}
\hline Componentes & 1 & 2 & 3 & Comunalidade \\
\hline Há regras sobre diversas situações na minha família. & 0,32 & & & 0,35 \\
\hline Eu sinto raiva da minha família. & & $-0,81$ & & 0,47 \\
\hline Viver com minha família é desagradável. & & $-0,80$ & & 0,35 \\
\hline Eu me sinto excluído da família. & & $-0,80$ & & 0,44 \\
\hline Eu sinto vergonha da minha família. & & $-0,79$ & & 0,58 \\
\hline Há ódio em minha família. & & $-0,76$ & & 0,46 \\
\hline Eu me sinto como um estranho na minha família. & & $-0,76$ & & 0,65 \\
\hline Minha família me irrita. & & $-0,72$ & & 0,49 \\
\hline Em minha família, há competitividade entre os membros. & & $-0,68$ & & 0,24 \\
\hline $\begin{array}{l}\text { Meus familiares só mostram interesse uns pelos outros } \\
\text { quando podem ter vantagens. }\end{array}$ & & $-0,64$ & & 0,36 \\
\hline $\begin{array}{l}\text { Meus familiares geralmente culpam alguém da família } \\
\text { quando as coisas não estão indo bem. }\end{array}$ & & $-0,58$ & & 0,20 \\
\hline Em minha família, brigamos e gritamos uns com os outros. & & $-0,56$ & & 0,45 \\
\hline Eu sinto que minha família não me compreende. & & $-0,46$ & & 0,52 \\
\hline $\begin{array}{l}\text { Acredito que minha família tenha mais problemas } \\
\text { emocionais do que as outras famílias. }\end{array}$ & & $-0,32$ & & 0,51 \\
\hline Minha família me dá tanta liberdade quanto quero. & & & 0,73 & 0,46 \\
\hline Meus familiares me deixam sair o tanto quanto quero. & & & 0,71 & 0,57 \\
\hline Em minha família, é permitido que eu faça as coisas & & & 0.65 & 0.54 \\
\hline Minha família permite que eu seja do jeito que eu quero ser. & & & 0,63 & 0,53 \\
\hline Meus familiares me permitem decidir coisas sobre mim. & & & 0,59 & 0,60 \\
\hline Minha família permite que eu me vista do jeito que eu quero. & & & 0,56 & 0,41 \\
\hline $\begin{array}{l}\text { Minha família me faz sentir que posso cuidar de mim, mesmo } \\
\text { quando estou sozinho(a). }\end{array}$ & & 0,30 & 0,38 & 0,37 \\
\hline Em minha família, temos privacidade. & & 0,31 & 0,37 & 0,51 \\
\hline Eigenvalues & & 11,2 & 3,7 & 2,5 \\
\hline Variância explicada & & 26,7 & 8,7 & 6,0 \\
\hline Total de variância explicada & & 41,4 & & \\
\hline
\end{tabular}

O fator que resultou da junção dos fatores posteriormente denominados afetividade e consistência passa a ter vinte e um itens e a ser denominado, agora, afetivo-consistente. O mesmo reflete perguntas que versam sobre a expressão de afetividade entre os membros familiares (verbal e não verbal), interesse, proximidade, acolhimento, comunicação, interação, respeito, empatia, clareza nas regras intrafamiliares, consistência de comportamentos e verbalizações e habilidades na resolução de problemas. O fator 2, denominado adaptação (anteriormente denominado de inadaptação, é o único fator que pontua invertido na correção) familiar, ficou composto por treze itens, sendo expresso por perguntas referentes a sentimentos e comportamentos negativos em relação à família, tais como raiva, isolamento, incompreensão, exclusão, não pertencimento, vergonha, irritação, relações agressivas (brigas e gritos), além da percepção de que os familiares 
competem entre si, são interesseiros e se culpam nos conflitos, ao invés de tentarem inter-relações mais pró-ativas. Por último, o fator denominado autonomia foi composto por oito itens, e possui questões que podem assinalar relações de confiança, liberdade e privacidade entre os membros. Os índices de confiabilidade, expressos pelo Alfa de Cronbach, demonstraram que o fator 1 apresentou o Alfa de 0,91, o fator 2, de 0,90, e o fator 3, de 0,78, além do valor de 0,93 para a escala total.

\section{Discussão}

Os índices de confiabilidade encontrados nas análises das duas configurações, quando do inventário como um todo, foram iguais, o que demonstra também a manutenção da consistência interna.
Como afirma Bray (1995), é de suma importância o desenvolvimento de instrumentos específicos que avaliem a percepção de suporte familiar no sentido de favorecer a sua utilização por profissionais e serviços preocupados em avaliar tal construto. A relação entre a disponibilização de instrumentos e seu conseqüente uso se traduz em um ciclo que se mantém em muitas sociedades, ou seja, o clínico pode não estar utilizando inventários na sua prática porque estes não existem e não são validados para a realidade de trabalho. Da mesma forma, a não existência de instrumentos que medem o construto de suporte familiar também propicia a sua não utilização por profissionais e serviços que poderiam utilizar tais inventários.

Nesse sentido, parece estar havendo uma mudança de paradigma no campo da avaliação psicológica nas últimas décadas, já que o próprio Conselho Federal de Psicologia vem desempenhando um papel fundamental no incentivo e na criação de comissões específicas que vêm discutindo e desenvolvendo critérios específicos para a avaliação de evidências de validade dos testes brasileiros (CFP-SATEPSI, 2006). Como aponta Oakland (2005), atualmente, os testes vêm sendo usados, comumente, por profissionais da saúde, educação, e outras áreas, sendo que a população já possui uma certa cultura de que será avaliada por testes em algum momento de suas vidas, tais como na avaliação de habilidades acadêmicas ou atitudes, interesse e qualificação vocacional e profissional e licença para habilitação, dentre outras.

Em relação à análise das duas configurações do IPSF, notaram-se algumas modificações em relação à primeira extração fatorial, tais como a junção de dois fatores em apenas um, além da exclusão de um item que possuía carga fatorial baixa para os parâmetros adotados. Tais modificações revelam mudança na organização estrutural do teste, mas não em seu objetivo ou nas qualidades psicométricas iniciais, já que as dimensões permanecem expressando o construto estudado (Baptista, 2005). Os índices de confiabilidade encontrados nas análises das duas configurações, quando do inventário como um todo, foram iguais, o que demonstra também a manutenção da consistência interna.

Inicialmente, é interessante notar que as dimensões encontradas nesta análise vêm ao encontro dos princípios teóricos e inventários internacionais destinados a mensurar tal construto. Pode-se acrescentar, a essa constatação, a afirmação que a forma como foram denominadas as dimensões e a maneira como os itens interagiram e se agruparam demonstram particularidades na comparação com os instrumentos internacionais existentes e as teorias (Epstein; Baldwin e Bishop, 1983; Parker, Tupling e Brown, 1979; Carver e Jones, 1992; 
Procidiano e Heller, 1983; Olson; Russel e Sprenkle, 1983).

Por exemplo, o family assessment device - $F A D$, desenvolvido por Epstein, Baldwin e Bishop (1983), é um dos instrumentos mais adotados para pesquisa e clínica nos Estados Unidos, e expressa o construto suporte familiar em sete dimensões, a saber, solução de problemas, comunicação, funções/papéis, receptividade afetiva, envolvimento afetivo, controle comportamental e funcionamento geral da família. Nesse sentido, observou-se, no IPSF, que as duas primeiras dimensões comportam grande parte das dimensões do FAD.

Já o parental bonding instrument - PBI, de Parker, Tupling e Brown (1979), preconiza duas grandes dimensões antagônicas, justificadas pela rejeição/indiferença x carinho e superproteção x permissão de autonomia. Assim, o IPSF, em sua primeira e em sua segunda dimensões, abarca o primeiro eixo do $\mathrm{PBI}$, e a terceira dimensão do IPSF aborda os mesmos conteúdos do segundo eixo do PBI.

Olson, Russell e Sprenkle (1983), em seu modelo circumplexo familiar, relatam que a coesão, a comunicação e a adaptabilidade traduziriam os principais componentes em um suporte familiar, lembrando que a coesão estaria relacionada com os vínculos, o processo de decisão, os interesses familiares comuns, os limites, as ligações entre as pessoas e os interesses nas atividades recreativas. A adaptabilidade seria a habilidade de o sistema familiar transformar a estrutura de poder e as regras nos relacionamentos em resposta a situações geradoras de estresse, também direcionada às situações de enfrentamento de problemas e, por último, a comunicação seria o ouvir reflexivo e suportivo, além da expressão e compartilhamento afetivo entre os membros familiares. Dessa forma, os dois primeiros fatores do IPSF também estariam bastante associados à proposta desses autores.
Finalmente, como relata Bray (1995), apesar das divergências teóricas e formatos dos instrumentos em avaliação de suporte familiar, podem ser distinguidos alguns pontos em comum quando da avaliação desse construto. A comunicação familiar seria uma faceta importante do suporte familiar, principalmente aquela relacionada com o tipo de comunicação, verbal e não verbal, a assertividade e a atenção dos membros, previstas na dimensão primeira do IPSF. Os conflitos também seriam um importante preditor de mau funcionamento familiar, incluindo-se aí as discordâncias entre os membros e a crítica, associadas particularmente aos afetos negativos, o que é abordado pela segunda dimensão do IPSF, ou seja, a adaptação familiar. A solução de problemas, a coesão/ vínculos, as regras e a afetividade também seriam destacadas pelo autor como facetas importantes na avaliação do suporte familiar e estariam especificamente relacionadas com a habilidade da família em resolver e apoiar os membros em situações-problema, a intensidade afetiva (proximidade) com que a família se interrelaciona, inclusive os interesses em comum, além da expressão emocional (verbal e não verbal) e a clareza nas regras familiares, que são também expressas pelas duas primeiras dimensões do IPSF. Bray (1995) aponta a faceta diferenciação/individuação, definida como a habilidade de os membros funcionarem autonomamente, o que pode ser parcialmente abordado pela terceira dimensão do IPSF.

É importante lembrar também que, apesar da construção e validação de diversos instrumentos, tal como o IPSF, os mesmos devem ser considerados formas paralelas e complementares do clínico e/ou pesquisador captar uma nuance do comportamento familiar. Como aponta Almeida (2005), a informação proposta por um teste está também na forma como o avaliador utiliza suas competências para avaliálas, já que ele deve possuir competência científica para inserir as informações provindas de um teste em um conjunto de informações 
tomadas a respeito da parcela do comportamento que se está medindo.

Sendo assim, o IPSF demonstrou ser um teste capaz de avaliar a percepção do suporte familiar, por intermédio de uma das evidências de validade, denominada validade de construto, segundo os Standards for Educational and Psychological Testing, produzido pela American Educational Research Association, American Psychological Association e National Council on Measurement in Education (AERA, APA \& NCME, 1999). Todos os três fatores também apresentaram índices de precisão considerados muito satisfatórios aos padrões da psicometria (Cronbach, 1951).

Os fatores encontrados na análise da segunda configuração representam os conteúdos de diversos instrumentos internacionais que avaliam o suporte familiar bem como de pressupostos teóricos tais como os desenvolvidos por Olson, Russell e Sprenkle (1983) a respeito das dimensões relevantes que fazem parte das relações de membros da família. É importante que outras evidências de validade, tais como convergente, discriminante, de conteúdo, dentre outras, possam ser pesquisadas, a fim de possibilitar outras qualidades psicométricas ao IPSF, já que a avaliação de evidências de validade de um instrumento demonstra ser um processo dinâmico. Um teste necessita de avaliações periódicas para se comprovar se, no decorrer do tempo e com diferentes populações, as normas e padronizações não necessitam ser modificadas e/ou atualizadas (Anastasi e Urbina, 2000). Por fim, faz-se necessária, também, a coleta de informações em diferentes amostras de diferentes regiões, faixas etárias e características, com a finalidade de se desenvolver a padronização do IPSF. 


\section{Makilim Nunes Baptista}

Coordenador e Docente do Programa de Pós-Graduação Strico-Sensu em Psicologia da Universidade São Francisco - Itatiba/SP

Doutor pelo Departamento de Psicologia Médica e Psiquiatria da Escola Paulista de Medicina Universidade Federal de São Paulo. Estrada da Rhodia Km 15, casa 33 - Condomínio Lagoa Serena - CEP 13085-850 - tel. 01145348040 - E-mail: makilim.baptista@saofrancisco.edu.br

ALLEN, K. R.; BLIESZNER, R.; ROBERTO, K. A. Family in the middle and later years: a review and critique of research in the 1990s. Journal of Marriage and the Family, Wisconcin, USA, v. 62, p.911-926, 2000.

ALMEIDA, L. S. Avaliação psicológica: exigências e desenvolvimento nos seus métodos. In: WECHSLER, S. M. e GUZZO, R. S. L. Avaliação Psicológica: Perspectiva Internacional. 2a ed. ver. e ampl. São Paulo: Casa do Psicólogo, 1977-2005, p. 47-65.

American Educational Research Association, American Psychological Association \& National Council on Measurement in Education. Standards for Educational and Psychological Testing. New York: American Educational Research Association, 1999.

ANASTASI, A.;URBINA, S. Testagem Psicológica. Porto Alegre: Artmed, 2000.

BAPTISTA, M. N. Desenvolvimento do Inventário de Percepção de Suporte Familiar (IPSF): estudos psicométricos preliminaries. PSICOUSF, São Paulo, v.10, no 1, p.11-19, 2005.

BRAY, J. H. Family assessment: current issues in evaluating families. Family Relations, Blacksburg, V.A. USA, v. 44, p. 469-477, 1995.

CARVER, M. D.;JONES W. H. The family satisfaction scale. Social Behavior and Personality, Palmerston North, New Zealand, v. 20, no 2, p.71-84, 1992

CLARK, L. La família: methological issues in the assessment of perinatal social support for Mexicans living in the United States. Social Science \& Medicine, 53, Leicester, England, p.1303-1320, 2001.

Conselho Federal de Psicologia - CFP - Sistema de Avaliação de Testes Psicológicos - SATEPSI. Acessado em 17/04/2006 http:// www.psicologia-online.org.br/

CRONBACH, L. J. Coefficient Alfa and the internal structure of tests. Psychometrika, Pittsburg, USA, v. 16, no 3, p. 297-334, 1951.

EPSTEIN, N. B.; BALDWIN, L. M.; BISHOP, D. S. The McMAster Family Assessment Device. Journal of Marital and Family Therapy, Fort Lauderdale, Florida, USA, v. 9, p.171-180, 1983.

FRANCO, N.; LEVITT, M. J. The social ecology of middle childhood: family support, friendship quality and self-esteem. Family Relations, , Blacksburg, V.A. USA, v. 47, no 4, p.315-321, 1998.

JOHNSON, J. G.; COHEN, P.; GOULD, M. S.; KASEN, S.; BROWN, J.; $\mathrm{BROOK}$, J. S. Childhood adversities, interpersonal difficulties and risk for suicide attempts during late adolescence and early adulthood Archives of General Psychiatry, Belmont, Massachusetts, USA, v.59, p. $741-749,2002$.

HARRIS, T. L.; MOLOCK, S. D. Cultural orientation, family cohesion and family support in suicide ideation and depression among AfricanAmerican college students. Suicide and Life-Threatening Behavior, Chicago, Illinois, USA, v.30, no 4, p. 341-353, 2000.

HILL, J.; FONAGY, P.; SAFIER, E.; SARGENT, J. The ecology of attachment in the family. Family Process, Rochester, USA, v. 42, no 2, p.205-221, 2003.

KASHANI, J. H.; CANFIELD, L. A.; BORDUIN, C. M.; SOLTYS, S M.;REID, J. C. Perceived family and social support: impact on children. Journal of American and Academy Child and Adolescent Psychiatry, Chicago, USA, v. 33, no 6, p.819-823, 1994.

KIRK, R. H. Family support: the roles of early years' centres. Children \& Society, Huddersfield, UK, v. 17, p. 85-99, 2003.

OAKLAND, T. Developing standardized tests. In: WECHSLER, S. Me GUZZO, R. S. L. Avaliação Psicológica: Perspective Internacional 2ª ed. ver. e ampl. São Paulo: Casa do Psicólogo, 2005, p. 121-144.

OLSON, D. H.; RUSSELL, C. S.; SPRENKLE, D. H. Circumplex model of marital and family systems: vi. Theoretical update. Family Process, Malden, USA, v. 22, p. 69-83, 1983.

PARKER, G., TUPLING, H. \& BROWN, L. B. A parental bonding instrument. British Journal of Medical Psychology, Biggleswade, UK, v.52, no 1 , p.1-10, 1979

PROCIDANO, E. M. \& HELLER K. Measures of perceived social support from friends and from family: three validation studies. American Journal of Community Psychology, East Lansing, Michigan, USA, v. 11, no 1, p.1-24, 1983

RETI, I. M.; SAMUELS, J. F.; EATON, W. W.; BIENVENU III, O. J.; COSTAJUNIOR, P. T. \& NESTADT, G. Influences of parenting on normal personality traits. Psychiatry Research, New York/ NY, USA, 111, p.5564,2002

SANTOS, T. M. M. Evidência de Validade entre Percepção de Suporte Familiar e Traços de Personalidade. Dissertação de mestrado não publicada. Programa de Pós-Graduação stricto sensu em Psicologia da Universidade São Francisco, Itatiba-SP, 2005.

STEIN, D.; WILLIAMSON, D. E.; BIRMAHER, B.; BRENT, D. A. KAUFMAN, J.; DAHL, R. E.; PEREL, J. M.; RYAN, N. D. Parent-child bonding and family functioning in depressed children at high risk and low for future depression. Journal of American and Academy Child and Adolescent Psychiatry, Chicago, USA, v.39, 11, p.1387-1395, 2000

XIAOLIAN, J.; CHAIWAN, S.; PANUTHAII, S.; YIJUAN, C.; LEI, Y. \& JIPING, L. Family support and self-care behavior of Chinese chronic obstructive pulmonary disease patients. Nursing and Health Sciences, Ube, Japão, 4, p. 41-49, 2002.

\section{Referências}

